\title{
The Interpersonal Impact of Social Comparison
}

\author{
Ming Ding1, Yaozhong Liư ${ }^{1}$, Qinghua Li ${ }^{2}$ \\ ${ }^{1}$ School of Management, Jinan University, Guangzhou, China \\ ${ }^{2}$ Heze University-Yuncheng, Heze, China \\ Email: 13422025180@163.com
}

How to cite this paper: Ding, M., Liu, Y. Z., \& Li, Q. H. (2018). The Interpersonal Impact of Social Comparison. Psychology, 9, 797-808

https://doi.org/10.4236/psych.2018.94051

Received: March 26, 2018

Accepted: April 24, 2018

Published: April 27, 2018

Copyright (c) 2018 by authors and Scientific Research Publishing Inc. This work is licensed under the Creative Commons Attribution International License (CC BY 4.0).

http://creativecommons.org/licenses/by/4.0/

\section{c) (i) Open Access}

\begin{abstract}
As a concept and phenomenon with strong interpersonal attributes, social comparison shouldn't be ignored its role in human interaction. This article outlines the interpersonal impact of social comparison, including pro-social behavior, conspicuous consumption, deception, and schadenfreude etc. According to the summary analysis, the upward comparison will bring more negative effects, and the downward comparison will bring more positive impacts. There have been some studies that have explored the psychological mechanisms of this process. Future research can make more exploration on the application scenes and psychological mechanisms.
\end{abstract}

\section{Keywords}

Social Comparison, Interpersonal Impact, Psychological Mechanism

\section{Introduction}

During half of the past century, researches about social comparison have focused on motives and standards of social comparison and its influence to individuals. However, little attentions have been paid on the interpersonal consequences brought by social comparison, such as the perception of others and the influence on self-other relationships etc. (Corcoran, Crusius, \& Mussweiler, 2011; Exline \& Lobel, 1999). As a concept and phenomenon with strong interpersonal attributes, social comparison shouldn't ignore its role in human interaction.

In modern society, social comparisons are inevitable. Many people follow the principle of keeping "low key" to avoid negative influence brought by social comparison. Managers have realized the negative impact of model motivation. It's meaningful to find out the interpersonal impact of social comparison and its psychological mechanisms. It's helpful to deal with interpersonal interactions and achieve our goals with proper strategies. 


\section{Individual Impact of Social Comparison}

Because comparisons with others are such a fundamental, ubiquitous, and robust human proclivity, it may not be surprising that for over fifty years social comparison has been a highly studied topic in social psychological research. Social comparison shapes people's self-evaluation in multiple and variable ways (Corcoran, Crusius, \& Mussweiler, 2011; Mussweiler, 2003). Self-perception, affective reactions, motivation, and behavior are all shaped by comparisons with others. Social comparisons are typically portrayed as strategic processes, which are executed to satisfy certain motives or goals (Taylor et al., 1996). Specifically, social comparison is mostly understood as a process which is engaged to fulfill fundamental needs such as self-evaluation, self-enhancement, and self-improvement (Tesser, 1988; Suls \& Wheeler, 2013). People looking at superior others generate feelings of relative depravation that one has fewer possessions or abilities than those people (Smith \& Pettigrew, 2011). In another study they were more motivated and showed a better performance after an upward than after a downward comparison (Seta, 1982). Research indicates that upward comparison with attractive body images increases depressive mood and anxiety about weight (Lee et al., 2014). Social comparisons in different directions may lead to positive and negative self-evaluation, i.e., assimilation and contrast effects. It depends mainly on information entering individual's self-evaluation system that is Selective Accessibility (SA) (Mussweiler, 2003). This paper, based on the analysis of the individual impact of social comparison, pays more attention to the interpersonal impact of social comparison.

\section{Interpersonal Impact of Social Comparison}

Social comparison will bring about positive interpersonal interaction as well as negative influence. According to the summary analysis, the upward comparison will bring more negative effects, and the downward comparison will bring more positive impacts. The outcome depends on many factors, such as individual characteristics, situation and comparison direction. This part talks about the situation and comparison direction.

\subsection{Pro-Social Behavior}

Pro-social behavior refers to acts that help people, make charitable donations, sacrifice themselves, and have little chance of getting rewards (Rosenhan, 1978). Many studies show that social comparison will affect the willingness of pro-social behavior. Klein (2003) found that people are more willing to help others after downward comparison. In the experiment, participants received feedback on the performance of tasks. After that, they provided clues for their peers to complete another experimental task. It was found that participants, who received positive social comparison feedback, were more willing to provide experimental peers with useful clues to complete the task. Van de Ven, Zeelenberg and Pieters (2010) manipulated the social comparison direction by setting the 
relative amount of experimental rewards obtained by the participants and their partners. They found that the winning party, who got extra rewards, will be more willing to accept the help request from the non-rewarded party.

In China, studies with similar conclusions have also been conducted. When participants are randomly asked to compare with those who are ranked first or last in their academic performance, compared with people after making upward comparison and no-comparison, participants after making downward comparison will increase the tendency to help others. In addition, the willingness to help others is not confined to the subject to be compared with. In a following study, they manipulate social comparisons through fictional intelligence test ranking feedback, and then measure the willingness of the participants to donate to strangers. The result shows that when people learn that their test scores are better than most people, they are more willing to make donations to unfamiliar others (Zheng, Peng, \& Peng, 2015).

\subsection{Cooperative Behavior}

Downward comparison will make people more cooperative. Compared with those who are ranked lower, People who are ranked higher are more willing to cooperate. Whether or not the comparison others is the person participating the later cooperation task, this phenomenon exists. Besides, this phenomenon is more pronounced in people with higher social tendencies (Gong \& Sanfey, 2017).

Previous researches have studied competition and cooperation separately. In fact, they ignore the "coopetitive" working relationship. It is very easy for employees to treat their colleagues as collaborators or competitors simultaneously. Small clues will change the behavior of employees. Small leads that cause upward comparison will reduce people's nominations to colleagues. The desire of them is to treat colleagues as competitors and reduce pro-social behavior (Milkman \& Schweitzer, 2012).

However, downside comparison has negative impact on cooperation as well. The higher a person's organization ranking is, the less cooperative the person's facial expression will be judged to be (Chen \& Myers, 2012). Leaders need to realize that their high status will affect their expressions which will influence others' willingness to cooperate.

\subsection{Conspicuous Consumption}

Individuals will make defensive responses to deal with the self-threat that social comparison brings. In the context of consumption, socially comparative information which is self-threatening can prompt consumers to lie (Argo, Katherine White, \& Dahl, 2006). It should be noted that it's the socially induced self-threatening that can leads to lies rather than social comparison itself. Social comparisons in areas of competence that are not related to consumption also lead to conspicuous consumption. Conspicuous consumption is used to make up 
for the psychological disadvantages and self-threat arise from comparisons. It is an alternative psychological demand satisfaction tool. When the sense of inferiority and threat is met through other self-assertion approaches, people will no longer make psychological compensation through conspicuous consumer behavior, which means self-threat will mediate the process (Zheng, Peng, \& Dai, 2014).

\subsection{Schadenfreude}

Social comparison may affect the perception of others. Schadenfrede means someone is delight with other people's misfortunes (Heider, 1958; Ortony, Clore, \& Collins, 1988). When the self-worth of someone is threatened by long-term or situational threats, he will be gloating. When the threat of self-evaluation is alleviated, the feeling of schadenfreude will be reduced. In addition, malicious envy will deepen the sense of joy in frustration with others. Self-evaluation threats and envy are all important factors inducing gloat. The motivation underneath schadenfrede is to allow people increase their sense of self-worth and eliminate the pain caused by envy (Dijk, Ouwerkerk, Smith, \& Cikara, 2015).

\subsection{Dishonesty}

Intuitively, people should cheat more when cheating is more lucrative. However, John et al. (2014) found that the effect of performance-based pay-rates on dishonesty depends on whether people can compare their pay-rate with others. Participants were paid with 5 cents or 25 cents per self-reported point randomly in a trivia task, and half of them were aware that they could have received the alternative pay-rate. People with lower pay-rates increased cheating when they were at the prospect of a higher pay-rate. Upward social comparisons that encourage the poorly compensated to cheat. Low pay-rates are, in and of themselves, unlikely to promote dishonesty. Social comparison is the key factor during the process.

\subsection{Friend Choosing}

Tesser et al. (1984) explored the influence of social comparisons on the choice of friends and examined whether people would choose friends who performed better than they did or who performed poorly on a major dimension. They found that children would make friends with people who are somewhat inferior in their important fields. This phenomenon supports Self Maintenance Model (SEM) (Tesser, 1988). However, it should be noticed that they make friends with people who are good at fields less relevant to them rather than perform badly at all fields. In general, their abilities are consistent. In another similar example, people select individuals with weaker ability in self-reliance areas as colleagues and exclude stronger individuals (Garcia, Song, \& Tesser, 2010).

\subsection{Recommendation}

When an individual faces a situation of providing advices to others, downside 
comparison may have a negative effect. Garcia, Song and Tesser (2010) set up three experimental scenarios in which individuals face two choices. One option is that the job candidate performs well in the individual advantage dimension, and middle in the less related dimension. The other option is that the job candidate performs middle in the individual superiority dimension, and well in the less related dimension. As a result, participants will make suggestions to prevent those who may exceed them in the field from entering the field in order to protect their own advantages. When the comparison field is very important for self-evaluation, or if its position is close to a certain standard, the self-sustaining motivation will be even stronger.

\subsection{Working Behavior}

Interpersonal interactions in workplace include information exchange, help, and cooperation. When unpleasant social comparisons are made in areas that are important for self-construction, employees will feel envy and unfair. Envy and perceived injustice can lead to harmful behaviors and produce interpersonal counterproductive work behaviors. Individuals with high self-esteem are particularly evident (Cohen-Charash \& Mueller, 2007). Poortvliet et al. (2009) explores the impact of achievement goals and ranking information on the willingness to exchange information. The result shows that individuals with performance goals are less likely to collaborate with each other in the case of high or low rankings. Individuals with the target have lower intentions for cooperation when rankings are higher. Their willingness to cooperate will increase when rankings are lower. Reciprocity orientation mediates this process.

Organizations often hope employees who compete for promotion and salary increase can cooperate with each other and give trust. However, the study finds that in the self-related field, both upward and downward comparisons may undermine trust. Upward comparison will damage emotional trust, and downward comparison will impair cognitive trust (Dunn, Ruedy, \& Schweitzer, 2012).

\section{Psychological Process}

\subsection{Moderator}

Many factors will moderate the interpersonal impact of social comparisons. They can be divided into two aspects. One is the social comparison structure and the other is the personal characteristics.

\section{1) Social Comparison Structure}

There has been many discussions about moderators on the impact of social comparisons on individuals, such as comparison direction, comparison relevance, and similarity of comparison others. These factors may also affect the interpersonal impact of social comparisons as is shown above. There are other studies to explore this subject. As the number of people participating in the social comparison increases, the individual will reduce competition motivation. When the proportion of success is constant, as the number of competitor increases, the 
individual will also consider the possibility of success greater, namely $\mathrm{N}$-effect. Research shows that as the number of students in the examination room increases, the average score of the test decreases. If participants believe that they compete with 10 people instead of 100 , they will show faster completion of the task. In addition, the higher social tendencies will show stronger $\mathrm{N}$ effect (Garcia \& Tor, 2010).

Comparative standards also moderate the interpersonal impact of social comparisons. As we know, people are more willing to provide experimental peers with useful clues to finish the task after making downward social comparison. This phenomenon is more pronounced when the standard of comparison is the average level of participants, rather than a single participant or objective criteria (Klein, 2003).

\section{2) Personal Characteristics}

Many personal characteristics affect the interpersonal impact of social comparisons. For example, social comparisons between same sexes can lead to more negative interpersonal behaviors. Women tend to punish successful women (for example, consider them unwelcome, hostile), so as to reduce the negative self-assessment results after upward comparison. Providing positive feedback on the likelihood of success for women will weaken this derogatory tendency (Parks-Stamm, Heilman, \& Hearns, 2008). Pellegrini (2007) pointed out that women would indirectly attack them because of envy of the beauty of other women and undermine their relationships and social reputation. Intersexual competition will cause people to intentionally or unintentionally depreciate the attribution of social comparison. People will tend to attribute attractive and successful same-sex gains to luck, and attribute the success of attractive heterosexuality to ability (Försterling, Preikschas, \& Agthe, 2007).

Perfectionist will reduce the affinity with comparison others after conducting a threatening social comparison, but it will not reduce the correlation between the comparative field and self-worth (Nicholls, 2011).

\subsection{Psychological Mechanism}

The positive interpersonal behavior after the comparison of the downside may be due to empathy and fear of being envied.

\section{1) Empathy}

Isen (1970) told the participants in the experiment that they performed above or below the average on the task of perceptual movement. It was found that those who believed that their performance was above average were more willing to be more helpful in the next situation. They call it "warmth glow of success", which means that positive emotions generated after downside comparison will spill over into other positive behaviors (Isen, 1970). Zheng et al. (2015) believe that this kind of "warm flow" is the empathy for the situation of others brought about by the downside comparison. The precondition for empathy for others is that people may pay attention to the plight and needs of others. In the compara- 
tive context of society, compared to the upward trend, people after making downward comparison will have abundant psychological resources and ability to pay attention to others and experience the situation of others, thus creating a feeling of empathy.

\section{2) Fear of being envied}

Outperforming others, although privately satisfying, can be a source of interpersonal strain. People believe that another person is making an upward comparison against the self and feel threatened by the competitive situation. The outperformer will experience concern about some facet of the other's response. The concern may be focused on the other, the self, or the relationship (Exline \& Lobel, 1999).

Envy is a frustrating experience that can lead to strong disgust and even malicious behavior (Schaubroeck \& Lam, 2004). According to the legitimacy of gaining advantage, envy is divided into benign envy and malicious envy (Cohen-Charash, 2009; Van de ven, Zeelenberg, \& Pieters, 2009). The right advantage can trigger goodwill. However, inequality often occurs, and it can become a serious threat for relations and team cohesion. Studies show that people who are in a dominant position are afraid of being stigmatized (Cohen-Charash, 2009) and thus show more interpersonal pro-social behavior to avoid possible ensuing destructive behaviors (Van de Ven et al., 2010). In addition to demonstrating pro-social behavior, other strategies to prevent negative outcomes include hiding advantages, underplaying, avoiding embarrassing people, and suggesting that embarrassing people are better in other areas (Parrott \& Rodriguez-Mosquera, 2008).

The reasons for the negative interpersonal influence caused by the upward comparison are mainly envy and the feeling of self-threat.

\section{1) Envy}

Envy is a self-threatening emotion by realizing someone itself inferior to others (such as ability, achievement, and assets), mixed with inferiority, hostility and even resentment. Envious people want to possess the advantage, or make the other party lose the advantage (Tangney \& Salovey, 1999; Parrott \& Smith, 1993: p. 906). Envy may induce interpersonal harm behaviors making envious people achieving three goals. The first is to harm people who are envied (Van de ven, Zeelenberg, \& Pieters, 2009). The second is to reduce the advantages of people being envied. The third is to protect self-esteem (Fein \& Spencer, 1997).

\section{2) Self-evaluation Threat}

According to SEM theory, maintaining or increasing positive self-assessment is the basic motivation for people (Tesser, 1988). Upward comparisons can create psychological threat perceptions (such as the feeling of incompetence, worthlessness, the feeling of uncontrollability, etc.). In order to cope with such psychological threats and maintain good self-evaluation, people always hope to compensate themselves through certain symbolic things or behaviors (Wicklund \& Gollwitzer, 1981, 2013; Zheng, Peng, \& Dai, 2014). Tesser (1988) showed that 
people would take various measures to reduce the self-assessment decline brought about by comparison. For example, reduce the interpersonal distance between the subject and comparison others, focus on other areas, and reduce the relevance of the comparative field (Tesser \& Campbell, 1980; Pleban \& Tesser, 1981).

Self affirmation theory believes that what people doesn't pursue good self-evaluation of a certain aspect (such as "I am a good student"), but a general sense of self-integrity, such as "I am a very nice person") (Sherman \& Cohen, 2006). Certain specific self-threats may affect people's psychology and behavior by affecting the overall self-perception of integrity. Therefore, the way people obtain and maintain positive self-evaluations is flexible (Cohen \& Sherman, 2014). Research finds that after making self-affirmation, people are less likely to evade threats or deny the importance of areas that pose a threat to self-evaluation (Vohs et al., 2013). On the contrary, self-affirmation allows individuals to respond to threats in a more constructive manner. For example, van Koningsbruggen et al. (2009) find that people are more willing to accept information that is threatening but beneficial to health after making self-affirmation. Similarly, Legault et al. (2012) find that self-affirming subjects pay more attention to their mistakes in cognitive tasks and learned from mistakes.

\section{3) Individualistic Mentality}

People affected by the upward comparative clues will experience individualistic mentality and regard their teammates as competitors (Triandis, 1989; 1994), thus creating negative interpersonal influences. Self-activated tends to increase social comparison (Stapel \& Tesser, 2001). Individuals who are competitive or oriented to competition will be more concerned with the psychological mechanisms of the differences between self and comparative goals (Stapel \& Koomen, 2005). Related studies have found that paying attention to oneself and treating oneself as part of an individual rather than a group and experiencing unpleasant social comparisons can harm interpersonal relationships (Dunn, Ruedy, \& Schweitzer, 2012; Garcia, Song, \& Tesser, 2010; Moran \& Schweitzer, 2008).

Once people's self-image is threatened, their responses are often to restore self-value to maintain their integrity. There are two approaches to deal with the situation. First, defend responses (such as denial, projection, and reverse formation) directly to reduce threats. This process is often automatic subconscious. The other is self-affirmation, that is, to compensate for the B-side with its A-side advantage (He, \& Huang, 2012). In fact, self-affirmation and defensive responses both are psychological strategies that individuals use to support and maintain the integrity of the self. They are interchangeable. Self-affirmation can reduce the individual's defense response (Critcher, Dunning, \& Armor, 2010).

\section{Future Research}

The interpersonal influence of social comparison is an important research subject. In future, more application scenarios can be explored. In addition, re- 
searches about psychological mechanisms are relatively fragmented and lack holistic framework.

\section{References}

Argo, J. J., Katherine White, \& Dahl, D. W. (2006). Social Comparison Theory and Deception in the Interpersonal Exchange of Consumption Information. Journal of Consumer Research, 33, 99-108. https://doi.org/10.1086/504140

Chen, P., \& Myers, C. G. (2012). The Hierarchical Face: Higher Rankings Lead to Less Cooperative Looks. Journal of Applied Psychology, 97, 479-486. https://doi.org/10.1037/a0026308

Cohen, G. L., \& Sherman, D. K. (2014). The Psychology of Change: Self-Affirmation and Social Psychological Intervention. Annual Review of Psychology, 65, 333-371. https://doi.org/10.1146/annurev-psych-010213-115137

Cohen-Charas, Y., \& Mueller, J. S. (2007). Does Perceived Unfairness Exacerbate or Mitigate Interpersonal Counterproductive Work Behaviors Related to Envy? Journal of Applied Psychology, 92, 666-680. https://doi.org/10.1037/0021-9010.92.3.666

Cohen-Charash, Y. (2009). Episodic Envy. Journal of Applied Social Psychology, 39, 2128-2173. https://doi.org/10.1111/j.1559-1816.2009.00519.x

Corcoran, K., Crusius, J., \& Mussweiler, T. (2011). Social Comparison: Motives, Standards, and Mechanisms. Theories in Social Psychology.

Critcher, C. R., Dunning, D., \& Armor, D. A. (2010). When Self-Affirmations Reduce Defensiveness: Timing Is Key. Personality \& Social Psychology Bulletin, 36, 947. https://doi.org/10.1177/0146167210369557

Dijk, W. W. V., Ouwerkerk, J. W., Smith, R. H., \& Cikara, M. (2015). The Role of Self-Evaluation and Envy in Schadenfreude. European Review of Social Psychology, 26, 247-282. https://doi.org/10.1080/10463283.2015.1111600

Dunn, J., Ruedy, N. E., \& Schweitzer, M. E. (2012). It Hurts Both Ways: How Social Comparisons Harm Affective and Cognitive Trust. Organizational Behavior \& Human Decision Processes, 117, 2-14. https://doi.org/10.1016/j.obhdp.2011.08.001

Exline, J. J., \& Lobel, M. (1999). The Perils of Outperformance: Sensitivity about Being the Target of a Threatening upward Comparison. Psychological Bulletin, 125, 307. https://doi.org/10.1037/0033-2909.125.3.307

Fein, S., \& Spencer, S. J. (1997). Prejudice as Self-Image Maintenance: Affirming the Self through Derogating Others. Journal of Personality \& Social Psychology, 73, 31-44. https://doi.org/10.1037/0022-3514.73.1.31

Försterling, F., Preikschas, S., \& Agthe, M. (2007). Ability, Luck, and Looks: An Evolutionary Look at Achievement Ascriptions and the Sexual Attribution Bias. Journal of Personality \& Social Psychology, 92, 775-788. https://doi.org/10.1037/0022-3514.92.5.775

Garcia, S. M., \& Tor, A. (2010). The N-Effect: More Competitors, Less Competition. Social Science Electronic Publishing, 20, 871-877.

Garcia, S. M., Song, H., \& Tesser, A. (2010). Tainted Recommendations: The Social Comparison Bias. Organizational Behavior \& Human Decision Processes, 113, 97-101. https://doi.org/10.1016/j.obhdp.2010.06.002

Gong, X., \& Sanfey, A. G. (2017). Social Rank and Social Cooperation: Impact of Social Comparison Processes on Cooperative Decision-Making. PLOS ONE, 12, e0175472. https://doi.org/10.1371/journal.pone.0175472 
He, Y., \& Huang, T. X. (2012). Potential Mechanisms and Influencing Factors of Self-Affirmation. Journal of Southwest University (Social Sciences Edition), 38, 53-61.

Heider, F. (1958). The Psychology of Interpersonal Relations. New York, NY: Wiley. https://doi.org/10.1037/10628-000

Isen, A. M. (1970). Success, Failure, Attention, and Reaction to Others: The Warm Glow of Success. Journal of Personality \& Social Psychology, 15, 294-301. https://doi.org/10.1037/h0029610

John, L. K., Loewenstein, G., \& Rick, S. I. (2014). Cheating More for Less: Upward Social Comparisons Motivate the Poorly Compensated to Cheat. Social Science Electronic Publishing, 123, 101-109. https://doi.org/10.1016/j.obhdp.2013.08.002

Klein, W. M. (2003). Effects of Objective Feedback and "Single Other" or "Average Other" Social Comparison Feedback on Performance Judgments and Helping Behavior. Personality \& Social Psychology Bulletin, 29, 418-429. https://doi.org/10.1177/0146167203251195

Lee, H. R., Lee, H. E., Choi, J., Kim, J. H., \& Han, H. L. (2014). Social Media Use, Body Image, and Psychological Well-Being: A Cross-Cultural Comparison of Korea and the United States. Journal of Health Communication, 19, 1343-1358. https://doi.org/10.1080/10810730.2014.904022

Legault, L., Al-Khindi, T., \& Inzlicht, M. (2012). Preserving Integrity in the Face of Performance Threat: Self-Affirmation Enhances Neurophysiological Responsiveness to Errors. Psychological Science, 23, 1455-1460. https://doi.org/10.1177/0956797612448483

Milkman, K. L., \& Schweitzer, M. E. (2012). Teetering between Cooperation and Competition: Social Comparisons and Peer Nominations. New York, NY: Social Science Electronic Publishing.

Moran, S., \& Schweitzer, M. E. (2008). When Better Is Worse: Envy and the Use of Deception. Negotiation and Conflict Management Research, 1, 3-29.

Mussweiler, T. (2003). Comparison Processes in Social Judgment: Mechanisms and Consequences. Psychological Review, 110, 472-489. https://doi.org/10.1037/0033-295X.110.3.472

Nicholls, E. (2011). Narcissism and the Self-Evaluation Maintenance Model: Effects of Social Comparison Threats on Relationship Closeness. Journal of Social Psychology, 151, 201-212. https://doi.org/10.1080/00224540903510852

Ortony, A., Clore, G. L., \& Collins, A. (1988). The Cognitive Structure of Emotions. Contemporary Sociology, 18, 2147-2153. https://doi.org/10.1017/CBO9780511571299

Parks-Stamm, E. J., Heilman, M. E., \& Hearns, K. A. (2008). Motivated to Penalize: Women's Strategic Rejection of Successful Women. Personality \& Social Psychology Bulletin, 34, 237-247. https://doi.org/10.1177/0146167207310027

Parrott, W. G., \& Rodriguez Mosquera, P. M. (2008). On the Pleasures and Displeasures of Being Envied. In R. Smith (Ed.), Envy: Theory and Research (pp. 117-132). New York, NY: Oxford University Press. https://doi.org/10.1093/acprof:oso/9780195327953.003.0007

Parrott, W. G., \& Smith, R. H. (1993). Distinguishing the Experiences of Envy and Jealousy. Journal of Personality \& Social Psychology, 64, 906-920. https://doi.org/10.1037/0022-3514.64.6.906

Pellegrini, A. D. (2007). Is Aggression Adaptive? Yes: Some Kinds Are and in Some Ways. In P. H. Hawley, T. D. Little, \& P. C. Rodkin (Eds.), Aggression and Adaptation: The Bright Side to Bad Behavior (pp. 85-105). Mahwah, NJ: Lawrence Erlbaum Associates. 
Pleban, R., \& Tesser, A. (1981). The Effects of Relevance and Quality of Another's Performance on Interpersonal Closeness. Social Psychology Quarterly, 44, 278-285. https://doi.org/10.2307/3033841

Poortvliet, P. M., Janssen, O., Yperen, N. W. V., \& Vliert, E. V. D. (2009). Low Ranks Make the Difference: How Achievement Goals and Ranking Information Affect Cooperation Intentions. Journal of Experimental Social Psychology, 45, 1144-1147. https://doi.org/10.1016/j.jesp.2009.06.013

Rosenhan, D. L. (1978). Toward Resolving the Altruism Paradox: Affect, Self-Reinforcement, and Cognition. In L. Wispe (Ed.), Altruism, Sympathy, and Helping (pp. 101-113). New York, NY: Academic Press.

Schaubroeck, J., \& Lam, S. S. K. (2004). Comparing Lots before and after: Promotion Rejectees' Invidious Reactions to Promotes. Organizational Behavior \& Human Decision Processes, 94, 33-47. https://doi.org/10.1016/j.obhdp.2004.01.001

Seta, J. J. (1982). The Impact of Comparison Processes on Coactors' Task Performance. Journal of Personality \& Social Psychology, 42, 281-291. https://doi.org/10.1037/0022-3514.42.2.281

Sherman, D. K., \& Cohen, G. L. (2006). The Psychology of Self-Defense: Self-Affirmation Theory. Advances in Experimental Social Psychology, 38, 183-242. https://doi.org/10.1016/S0065-2601(06)38004-5

Smith, H. J., \& Pettigrew, T. F. (2011). Relative Deprivation Theory. The Encyclopedia of Peace Psychology. https://doi.org/10.1002/9780470672532.wbepp238

Stapel, D. A., \& Koomen, W. (2005). Competition, Cooperation, and the Effects of Others on Me. Journal of Personality \& Social Psychology, 88, 1029-1038.

https://doi.org/10.1037/0022-3514.88.6.1029

Stapel, D. A., \& Tesser, A. (2001). Self-Activation Increases Social Comparison. Journal of Personality \& Social Psychology, 81, 742-750. https://doi.org/10.1037/0022-3514.81.4.742

Suls, J., \& Wheeler, L. (2013). Handbook of Social Comparison: Theory and Research. Berlin: Springer Science \& Business Media.

Tangney, J. P., \& Salovey, P. (1999). Problematic Social Emotions: Shame, Guilt, Jealousy, and Envy.

Taylor, S. E., Wayment, H. A., \& Carrillo, M. (1996). Social Comparison, Self-Regulation, and Motivation. In R. M. Sorrentino, \& E. T. Higgins (Eds.), Handbook of Motivation and Cognition, Vol. 3. The Interpersonal Context (pp. 3-27). New York, NY: Guilford Press.

Tesser, A. (1988). Toward a Self-Evaluation Maintenance Model of Social Behavior. Advances in Experimental Social Psychology, 21, 181-227. https://doi.org/10.1016/S0065-2601(08)60227-0

Tesser, A., \& Campbell, J. (1980). Self-Definition: The Impact of the Relative Performance and Similarity of Others. Social Psychology Quarterly, 43, 341-347. https://doi.org/10.2307/3033737

Tesser, A., Campbell, J., \& Smith, M. (1984). Friendship Choice and Performance: Self-Evaluation Maintenance in Children. Journal of Personality \& Social Psychology, 46, 561-574. https://doi.org/10.1037/0022-3514.46.3.561

Triandis, H. C. (1989). The Self and Social Behavior in Differing Cultural Contexts. Psychological Review, 96, 506-520.

Triandis, H. C. (1994). Culture and Social Behavior. Lawrence Erlbaum Associates, 3, 84-89. 
Van Koningsbruggen, G. M., Das, E., \& Roskos-Ewoldsen, D. R. (2009). How Self-Affirmation Reduces Defensive Processing of Threatening Health Information: Evidence at the Implicit Level. Health Psychology, 28, 563-568.

https://doi.org/10.1037/a0015610

Van, d. V. N., Zeelenberg, M., \& Pieters, R. (2009). Leveling up and down: The Experiences of Benign and Malicious Envy. Emotion, 9, 419-429. https://doi.org/10.1037/a0015669

Van, d. V. N., Zeelenberg, M., \& Pieters, R. (2010). Warding off the Evil Eye: When the Fear of Being Envied Increases Prosocial Behavior. Psychological Science, 21, 1671-1677. https://doi.org/10.1177/0956797610385352

Vohs, K. D., Park, J. K., \& Schmeichel, B. J. (2013). Self-Affirmation Can Enable Goal Disengagement. Journal of Personality and Social Psychology, 104, 14-27.

https://doi.org/10.1037/a0030478

Wicklund, R. A., \& Gollwitzer, P. M. (1981). Symbolic Self-Completion, Attempted Influence, and Self-Deprecation. Basic and Applied Social Psychology, 2, 89-114. https://doi.org/10.1207/s15324834basp0202_2

Wicklund, R. A., \& Gollwitzer, P. M. (2013). Symbolic Self Completion. Abingdon-on-Thames: Routledge.

Zheng, X. Y., Peng, S. Q., \& Dai, S. S. (2014). Impact of Social Comparison on Conspicuous Consumption: A Psychological Compensation Perspective. Journal of Marketing Science, 10, 19-31.

Zheng, X., Peng, S., \& Peng, L. (2015). Feeling Better and Becoming More Benevolent: Impact of Social Comparison on Prosocial Behavior. Acta Psychologica Sinica, 47, 243-250. https://doi.org/10.3724/SP.J.1041.2015.00243 